\title{
Association of risk factors with primary open angle glaucoma in adults over the age of $\mathbf{4 0}$
}

\author{
Arturo Gálvez-Rosas ${ }^{1}$, Aurelio Tirzo Serrano-Miranda², Carlos Ridaura-Valencia², \\ Eva Elizabeth Mundo-Fernández ${ }^{3}$ and Everardo Barojas-Weber ${ }^{3}$ \\ ${ }^{1}$ Division of Neurosciences; ${ }^{2}$ Hospital Epidemiological Surveillance-Sociomedical Research Unit; ${ }^{3}$ Ophthalmology Department, Instituto Nacional de \\ Rehabilitación, Ciudad de México, Mexico
}

\begin{abstract}
Objective: To determine the association of systemic diseases, as well as smoking and alcohol with primary open-angle glaucoma (POAG) in adults over 40 years age. Method: A revision of the records of patients older than 40 years aged who had been diagnosed with glaucoma, which were selected at the outpatient care dept. Information was obtained through the automated hospital information system, which included socio-demographic and clinical variables. Data base was created and was processed by SPSS V20 program. Results: 1,020 patient, 548 (53.7\%) with a diagnosis of POAG, mean age of patients $73.2 \pm 11.16$ years, of which 193 (35.2\%) were male and 355 (64.8\%) female. A significant relationship was found between POAG and increasing age $(p=0.000)$, diabetes mellitus $(p=0.056)$ and hypertension $(p=0.098)$. While no relationship was found between POAG and cancer, smoking and alcohol intake was found. Conclusions: These results display the need of carrying out more specific studies of causal type to establish best possible partnerships and thus carry out prevention programs for early diagnosis.
\end{abstract}

KEY WORDS: Risk factor. Primary open-angle glaucoma. Epidemiologic study. Adults.

\section{Introduction}

Glaucoma is a complex and heterogeneous disease, characterized by progressive degeneration of retinal ganglion cells and their axons at specific regions $^{1,2}$. Worldwide, it is the second cause of blindness, and it affects more than 70 million people ${ }^{3}$. Among the different types, primary open-angle glaucoma (POAG) is the most common ${ }^{4}$, which is a multifactorial condition ${ }^{5,6}$ for which triggering risk factors have been observed, such as family history ${ }^{7}$, old age $^{8}$, increased intraocular pressure (IOP) $)^{9,10}$, type 1 or 2 diabetes mellitus $(\mathrm{DM})^{11}$, arterial hypertension $(\mathrm{AH})^{12}$, alcohol consumption ${ }^{13}$ and smoking ${ }^{14}$, among others.

In Mexico, only few studies have been carried out on the prevalence of glaucoma in different zones of the country, and they address only risk factors related to $\mathrm{DM}, \mathrm{AH}$ and family history ${ }^{15,16}$. For example, the study conducted by Gilbert-Lucido et al. ${ }^{17}$ in Mexico City reported that POAG was related with a family history thereof in $15 \%$ of cases ( $p=0.016$ ), with the following figures being established for $\mathrm{DM}$ and $\mathrm{AH}$ : $22.7 \%$ $(n=110) ; p=0.054)$ and $33.9 \%(n=127)$, respectively ${ }^{17}$. Since there are no studies focused on risk factors for glaucoma in Mexico, we consider performing this type of studies in our populationto be necessary in order to try to prevent the progression of this disease.

\section{Method}

Patients with newly-diagnosed glaucoma were enrolled via Mexico City's Instituto Nacional de

\author{
Correspondence: \\ Arturo Gálvez-Rosas \\ Avda. México-Xochimilco, 289 \\ Col. Arenal de Guadalupe, Del. \\ Tlalpan C.P. 14389, Ciudad de México, \\ México \\ E-mail: glvezarturo@yahoo.com.mx
}

Date of reception: 18-07-2016

Date of acceptance: 08-08-2016

DOI://dx.doi.org/10.24875/GMM.M18000110
Gac Med Mex. 2018;154:31-34

Contents available at PubMed www.gacetamedicademexico.com 
Rehabilitación (INR) ophthalmology department outpatient clinic within the 2010-2012 period. Information was obtained through the hospital automated information system, where the following patient data were collected: name, age, gender, family history, DM, AH, cancer, alcohol consumption and smoking. Ophthalmologic data included visual acuity, both eyes' IOP, biomicroscopy, gonioscopy and fundoscopy. The patients were divided in two groups: with POAG and with other glaucomas (OG; primary angle-closure glaucoma, neovascular glaucoma, secondary pseudoexfoliative glaucoma, suspected glaucoma and other secondary glaucomas) according to diagnostic criteria by means of imaging and clinical studies. The groups were compared in terms of glaucoma, $\mathrm{DM}, \mathrm{AH}$, cancer, alcohol consumption and smoking. The procedures were conducted according to the Declaration of Helsinki and the study was approved by the INR research committee (registry number; 33/13).

Male and female gender patients, with an age $\geq 40$ years, with clinical diagnosis of glaucoma established and confirmed by the INR ophthalmology department, with characteristics of damage to the optic disc due to its cup/disc ratio, with typical visual field loss and IOP measurement by means of applanation tonometry were included. Exclusion criteria were: patients without confirmed clinical diagnosis and with incomplete medical record.

Data were analyzed with the statistical package SPSS $V_{20}$, and descriptive statistics was performed by means of central tendency tests, and to assess for possible associations, the chi-square test, Student's t-test and logistic regression analysis were used. The data epidemiological analysis Epidat $V_{4.1}$ program was used for the difference between proportions. A $p$-value $<0.05$ was considered to be statistically significant.

\section{Results}

A total of 1020 glaucoma-diagnosed patients were analyzed. The most common type of glaucoma was found to be POAG, with 548 cases $(53.7 \%)$. As for gender, 193 were males (35.2\%) and 355 were females (64.8\%) (Table 1). Patients were divided in two groups: with POAG and with OG. Associations between POAG and age and other factors are shown in table 2. In this sense, there was association between POAG and old age $(p=0.000)$, DM $(p=0.056)$ and $\mathrm{AH}$ (0.098). On the other hand, no significant difference was found for POAG between males and females $(p=0.192)$ (Table 3).
Table 1. Prevalence of primary open-angle glaucoma according to gender

\begin{tabular}{lccc}
\hline Gender & POAG & OG & TOTAL \\
\hline Female, n (\%) & $355(64.8 \%)$ & $324(68.6 \%)$ & $679(66.5 \%)$ \\
Male, n (\%) & $193(35.2 \%)$ & $148(31.4 \%)$ & $341(33.5 \%)$ \\
Total, n (\%) & $548(53.7 \%)$ & $472(46.3 \%)$ & $1020(100 \%)$ \\
\hline
\end{tabular}

OG: other glaucomas (primary angle-closure glaucoma, neovascular glaucoma, secondary pseudoexfoliative glaucoma, suspected glaucoma, other secondary glaucomas: POAG: primary open-angle glaucoma.

Average age in patients with POAG was $73.2 \pm$ 11.16 years, and $67.8 \pm 9.9$ years in those with $O G$. IOP average was $17.1 \pm 7.1 \mathrm{mmHg}$ in both groups, with no statistical significance, which may be due to the fact that both are groups of heavily treatment-experienced patients from other hospitals (Table 1).

The POAG-correlated logistic regression analysis results are presented in table 4 . After adjusting for age, the relationship between POAG and age was statistically significant $(p=0.000)$. Each year of age increase was found to increase the likelihood of having POAG by $4.6 \%$ in comparison with the OG group, with this association being statistically significant (odds ratio [OR]: 1.046; 95\% confidence interval [Cl]: 1.034-1.059; $p=0.001$ ). In addition, taking patients of the $40-49$ years age group as reference, a statistically significant association for each life-decade can be observed to exist: the 50-59 years' group has 2.051fold higher probability of having POAG (OR: 2.051; $95 \% \mathrm{Cl}: 0.937-4.490 ; p=0.07$ ), the $60-69$ years group has 3.283 -fold higher probability (OR: $3.283 ; 95 \% \mathrm{Cl}$ : $1.558-6.977 ; p=0.002)$, the $70-79$ years' group has 5.474-fold higher probability (OR: $5.474 ; 95 \% \mathrm{Cl}$ : $2.635-11.371 ; p=0.001$ ), and the 80 -year and older group has 6.972-fold higher probability (OR: 6.972 ; $96 \%$ Cl: 3.287-14.781; $p=0.001$ ).

\section{Discussion}

Glaucoma is an irreversible disease that has no symptoms until advanced stages, and is one of the leading causes of blindness in the world, which affects the population older than 40 years and limits their daily activities.

In this investigation, where risk factors for POAG were assessed, the first factor to be analyzed was age, and the logistic regression analysis demonstrated that old age is a risk factor associated with POAG and that, with each decade of life, the percentage of glaucoma increases progressively. There are several reports that confirm that the prevalence of glaucoma 
Table 2. Association between primary open-angle glaucoma and risk factors

\begin{tabular}{|c|c|c|c|c|}
\hline & $\begin{array}{c}\text { POAG } \\
(n=548)\end{array}$ & $\begin{array}{c}O G \\
(n=472)\end{array}$ & $x 2$ & $\mathbf{p}$ \\
\hline Age, average \pm SD & 73.2 & 67.8 & 7.8 & 0.000 \\
\hline $\mathrm{IOP}$, average $\pm \mathrm{SD}$ & $17.1 / 17.2$ & $17.0 / 17.1$ & $0.164 / 0.256$ & $0.870 / 0.871$ \\
\hline Gender, female/male & $355 / 193$ & $324 / 148$ & 1.7 & 0.192 \\
\hline $\mathrm{AH}, \mathrm{n}(\%)$ & $57(10.4 \%)$ & $65(14.0 \%)$ & 2.734 & 0.098 \\
\hline DM, n (\%) & $100(18.2 \%)$ & $109(23.1 \%)$ & 3.654 & 0.056 \\
\hline Cancer, n (\%) & $25(4.5 \%)$ & $24(5.1 \%)$ & 0.152 & 0.697 \\
\hline Smoking, n (\%) & $78(14.2 \%)$ & $71(15.0 \%)$ & 0.133 & 0.715 \\
\hline Alcohol consumption, n (\%) & $62(11.3 \%)$ & $46(9.7 \%)$ & 0.659 & 0.417 \\
\hline
\end{tabular}

AH: arterial hypertension; DM: diabetes mellitus; IOP: intraocular pressure; OG: other glaucomas (primary angle-closure glaucoma, neovascular glaucoma, secondary pseudoexfoliative glaucoma, suspected glaucoma, other secondary glaucomas; POAG: primary open-angle glaucoma; SD: standard deviation.

Table 3. Primary open-angle glaucoma prevalence according to gender and age

\begin{tabular}{lccc}
\hline Age (years) & Male & Female & Total \\
\hline $40-49$ & $23.5 \%(4 / 17)$ & $20.7 \%(6 / 29)$ & $21.7 \%(10 / 46)$ \\
$50-59$ & $45.2 \%(19 / 42)$ & $32.2 \%(30 / 93)$ & $33.3 \%(49 / 135)$ \\
$60-69$ & $53.0 \%(44 / 83)$ & $44.8 \%(70 / 156)$ & $47.7 \%(114 / 239)$ \\
$70-79$ & $62.1 \%(77 / 124)$ & $59.4 \%(145 / 244)$ & $60.3 \%(222 / 368)$ \\
80 and older & $65.3 \%(49 / 75)$ & $66.2 \%(104 / 157)$ & $65.9 \%(153 / 232)$ \\
Total & $56.6 \%(193 / 341)$ & $52.3 \%(355 / 679)$ & $53.7 \%(548 / 1020)$ \\
\hline$z=1.304: p=0.192 ; 95 \% \mathrm{Cl:}-0.021-0.108$. &
\end{tabular}

increases with age ${ }^{18-20}$. An additional finding also revealed by this study is that, for each year of age, the probability of having POAG increases 4.6 -fold, in comparison with the OG groups.

The Blue Mountains Eyes trial reported a statistically significant relationship between POAG, DM and $A H^{21,22}$. In our research, a slight relationship between $\mathrm{POAG}, \mathrm{DM}$ and $\mathrm{AH}$ was found, and no significant association was found with cancer. Many studies have found a positive relationship between POAG, DM and $\mathrm{AH}^{23-27}$, but many others have failed to find any relationship ${ }^{28-32}$. In conclusion, the relationship between POAG and both vascular conditions is still controversial, and carrying out other studies about causality is necessary.

Among personal habits, alcohol consumption and smoking were investigated, with no association with POAG being found. As with systemic diseases, there are studies reporting a positive association between POAG, smoking and alcohol consumption ${ }^{33-36}$, but a similar number of other studies don't find any relationship, which is highly arguable $e^{37-40}$.
Table 4. Association between primary open-angle glaucoma and risk factors by means of logistic regression analysis

\begin{tabular}{|c|c|c|c|}
\hline Variable & OR & $95 \% \mathrm{Cl}$ & $P$ \\
\hline \multicolumn{3}{|l|}{ Gender } & Q \\
\hline Female (ref.) & 1 & & 폰 \\
\hline Male & 0.174 & $0.916-1.546$ & 0.192 \\
\hline \multicolumn{3}{|l|}{ Age (years) } & 은 \\
\hline 40-49 (ref.) & 1 & & $\frac{\varrho}{\alpha}$ \\
\hline $50-59$ & 2.051 & $0.937-4.490$ & 0.072 \\
\hline $60-69$ & 3.283 & $1.558-6.977$ & 0.002 \\
\hline $70-79$ & 5.474 & $2.635-11.371$ & 0.000 \\
\hline 80-older & 6.972 & $3.287-14.781$ & 0.000 \\
\hline \multicolumn{3}{|l|}{$\mathrm{AH}$} & or \\
\hline Absent (ref.) & 1 & & 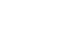 \\
\hline Positive & -0.259 & $0.535-1.114$ & 0.167 \\
\hline \multicolumn{3}{|l|}{ DM } & 을 \\
\hline Absent (ref.) & 1 & & 닫 \\
\hline Positive & -0.181 & $0.621-1.120$ & 0.227 \\
\hline \multicolumn{3}{|l|}{ Cancer } & g \\
\hline Absent (ref.) & 1 & & $\underline{J}$ \\
\hline Positive & -0.232 & $0.467-1.348$ & 0.271 \\
\hline Smoking & & & $\frac{O}{2}$ \\
\hline Absent (ref.) & 1 & & (1) \\
\hline Positive & 0.065 & $0.662-1.348$ & 0.715 \\
\hline \multicolumn{3}{|l|}{ Alcohol consumption } & 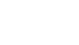 \\
\hline Absent (ref.) & 1 & & $\subsetneq$ \\
\hline Positive & 0.167 & 0.790-1.768 & 0.167 \\
\hline
\end{tabular}

AH: arterial hypertension; DM: diabetes mellitus; OR: odds ratio; $95 \%$ Cl: $95 \%$ confidence interval.

Finally, an average value of $17.1 \mathrm{mmHg}$ was found for both eyes' IOP, which does not correspond to a risk factor, a facts that is reported in several studies ${ }^{41}$. This is probably due to the fact that most studied patients come from other institutions, where they have been treated, or else they underwent some previous cataract surgery, and at that moment was the glaucoma detected without having shown any symptoms. 
In this study, some factors were not analyzed, including myopia, corneal thickness, optical disc hemorrhage, migraine, etc. On the other hand, vascular pathologies were dichotomously investigated, without taking blood and pressure values into account. One of the variables with the highest relevance in glaucoma is IOP, but so far there is no consensus on measurement position and timing, or on fluctuations; in this study, the value was only taken at diagnosis.

\section{Conclusions}

Given that glaucoma in older adults is a multifactorial condition, continuing with this type of studies is necessary in order to look for other risk factors that allow for the course of disease to be modified and being able to opportunely establish an adequate diagnosis, and thus prevent people from experiencing blindness at early ages.

\section{Conflicts of interests}

None of the authors have any conflicts of interests relevant to this publication.

\section{References}

1. Sharts-Hopko NC, Glynn-Milley C. Primary open-angle glaucoma; catching and treating the sneak thief of sight. Am J Nurs. 2009;109:40-7.

2. Fuse N. Genetic bases for glaucoma. Tohoku J Exp Med. 2010;221:1-10

3. Quigley HA, Broman AT. The number of people with glaucoma worldwide in 2010 and 2020. Br J Ophthalmol. 2006;90:262-7.

4. Rao KN, Nagireddy S, Chakrabarti S. Complex genetic mechanisms in glaucoma: an overview. Indian J Ophthalmol. 2011;59(Suppl): S31-S42.

5. Coleman AL, Kodjebacheva G. Risk factors for glaucoma needing more attention. Open Ophthalmol J. 2009;3:38-42.

6. Boland MV, Quigley HA. Risk factors and open-angle glaucoma: classification and application. J Glaucoma. 2007;16:406-18.

7. Kong $X$, Zhu W, Chen X, et al. Familial aggregation of primary open angle glaucoma in Shanghai, China. Mol Vis. 2013;19:1859-65.

8. Voleti VB, Hubschman JP. Age-related eye disease. Maturitas. 2013;75: 29-33.

9. Miglior S, ZeyenT, Pfeiffer N, et al. Results of the European glaucoma prevention study. Ophthalmology. 2005;112:366-75.

10. Kooner KS, Albdoor M, Cho BJ, et al. Risk factors for progression to blindness in high tension primary open angle glaucoma: comparison of blind and nonblind subjects. Clin Ophthalmol. 2008;2:757-62.

11. Coleman AL, Miglior S. Risk factors for glaucoma onset and progression. Surv Ophthalmol. 2008:53(Suppl 1):S3-S10.

12. Yanagi $M$, Kawasaki R, Wang JJ, et al. Vascular risk factors in glaucoma: a review. Clin Experiment Ophthalmol. 2011;39:252-8.

13. Klein BE, Klein R, Ritter LL. Relationship of drinking alcohol and smoking to prevalence of open-angle glaucoma. The Beaver Dam Eye Study. Ophthalmology. 1993;100:1609-13.

14. Wang $D$, Huang $Y$, Huang $C$, et al. Association analysis of cigarette smoking with onset of primary open-angle glaucoma and glaucoma-related biometric parameters. BMC Ophthalmology. 2012;12:1-5.
15. Velasco-Gallegos G, Noriega-Ramirez ME. Prevalencia del glaucoma en población definida en Monterrey, Nuevo León, México. Rev Mex Oftalmol. 2002;76:24-9

16. López-López G, Gastélum-Guerrero J. Prevalencia de glaucoma primario en la coordinación universitaria del Hospital Civil de Culiacán en el periodo 2003-2005. Bol Med UAS. 2006;12:12-5

17. Gilbert-Lucido ME, García-Huerta M, Ruiz-Quintero N, et al. Estudio epidemiológico de glaucoma en población mexicana. Rev Mex Oftalmol. 2010;84:86-90.

18. Gálvez-Rosas A, Serrano-Miranda AT, Mundo-Fernández EE, et al. Determinación de la frecuencia del glaucoma primario de ángulo abierto en pacientes mayores de 40 años en una institutción de tercer nivel de la ciudad de México. Investigación en Discapacidad. 2015;4:65-70.

19. Kahn HA, Milton RC. Alternative definitions of open-angle glaucoma. Effect on prevalence and associations in the Framingham eye study. Arch Ophthalmol. 1980;98:2172-7.

20. Schoff EO, Hattenhauer MG, Ing HH, et al. Estimated incidence of open-angle glaucoma in Olmsted County, Minnesota. Ophthalmology. 2001;108:882-6.

21. Mitchel P, Smith W, Chey T, et al. Open-angle glaucoma and diabetes - The Blue Mountains Eye study, Australia. Ophthalmology. 1997;104:712-8.

22. Mitchell $P$, Lee AJ, Rochtchina $E$, et al. Open-angle glaucoma and systemic hypertension: the Blue Mountains Eye study. J Glaucoma. 2004;13:319-26

23. Armstrong JR, Daily RK, Dobson $\mathrm{HL}$, et al. The incidence of glaucoma in diabetes mellitus. A comparison with the incidence of glaucoma in the general population. Am J Ophthalmol. 1960;50:55-63.

24. Klein BE, Klein R, Jensen SC. Open-angle glaucoma and older-onse diabetes. The Beaver Dam Eye Study. Ophthalmology. 1994:101:1173-7.

25. Dielemans I, de Jong PT, Stolk R, et al. Primary open-angle glaucoma, intraocular pressure and diabetes mellitus in the general elderly population. The Rotterdam study. Ophthalmology. 1996;103:1271-5.

26. Bonomi L, Marchini G, Marrafa M, et al. Vascular risk factors for primary open angle glaucoma: the Egna-Neumarkt study. Ophthalmology. 2000;107:1287-93.

27. Hulsman CA, Vingerling JR, Hofman A, et al. Blood pressure arterial stiffness, and open-angle glaucoma: the Rotterdam study. Arch Ophthalmol. 2007; 125:805-12.

28. Tielsch JM, Katz J, Quigley HA, et al. Diabetes, intraocular pressure, and primary open-angle glaucoma in the Baltimore eye survey. Ophthalmology. 1995;102:48-53.

29. Kahn HA, Milton RC. Alternative definitions of open-angle glaucoma. Effect on prevalence and associations in the Framingham eye study. Arch Ophthalmol. 1980;98:2172-7.

30. Gordon MO, Beiser JA, Brandt JD, et al. The ocular hypertension treatment study. Baseline factors that predict the onset of primary open-angle glaucoma. Arch Ophthalmol. 2002;120:714-20.

31. Leske MC, Wu SY, Hennnis A, et al. Risk factor for incident open-angle glaucoma. The Barbados Eye studies. Ophthalmology. 2008;115:85-93.

32. Nakano T, Tatemichi M, Miura $Y$, et al. Long-term physiologic changes of intraocular pressure: a 10 year longitudinal analysis in young and middle-aged Japanese men. Ophthalmology. 2005;112:609-16.

33. Mehra KS, Roy PN, Khare BB, et al. Tobacco smoking and glaucoma. Ann Ophthalmol. 1976;8:462-4.

34. Wilson MR, Hertzmark E, Walker AM, et al. A case-control study of risk factor in open angle glaucoma. Arch Ophthalmol. 1987;105:1066-71.

35. Wang S, Wang JJ, Wong TY. Alcohol and eye diseases. Surv Ophthalmol. 2008;53:512-25.

36. Chiotoroiu SM, Pop de Popa D, Stefaniu GI, et al. The importance of alcohol abuse and smoking in the evolution of glaucoma disease. J Med Life. 2013;6:226-9.

37. Kang JH, Pasquale LR, Rosner BA, et al. Prospective study of cigarette smoking and the risk of primary open-angle glaucoma. Arch Ophthalmol. 2003:12:1762-8.

38. Edwards R, Thornton J, Ajit R, et al. Cigarette smoking and primary open angle glaucoma: a systematic review. J Glaucoma. 2008;17:558-66.

39. Leske MC, Warheit-Roberts L, Wu SY. Open-angle glaucoma and ocular hypertension: the Long Island Glaucoma case-control study. Ophthalmic Epidemiol. 1996;3:85-96.

40. Ponte F, Gioffre G, Giammanco R, et al. Risk factors of ocular hypertension and glaucoma. The Casteldaccia Eye study. Doc Ophthalmol. 1994;85:203-10

41. Bengtsson B, Leske MC, Hyman L, et al. Fluctuation of intraocular pressure and glaucoma progression in the early manifest glaucoma trial. Ophthalmology. 2007;114:205-9. 